\title{
Carbon Nanoparticles for Identifying Lymph Nodes during Surgery in Colorectal Cancer: A Meta-Analysis
}

\author{
Miao Liu1, Ai Shen², Wei Li1', Lihui Chen'1, Xiufeng Chen1', Hao Sun ${ }^{*}$ \\ ${ }^{1}$ Gastrointestinal Cancer Center, Chongqing University Cancer Hospital \& Chongqing Cancer Institute \& Chongqing Cancer \\ Hospital, Chongqing, China \\ ${ }^{2}$ Department of Hepatobiliary Surgery, Chongqing University Cancer Hospital \& Chongqing Cancer Institute \& Chongqing \\ Cancer Hospital, Chongqing, China \\ Email: *sunhao68@sina.com
}

How to cite this paper: Liu, M., Shen, A., Li, W., Chen, L.H., Chen, X.F. and Sun, H. (2019) Carbon Nanoparticles for Identifying Lymph Nodes during Surgery in Colorectal Cancer: A Meta-Analysis. Journal of Cancer Therapy, 10, 134-145.

https://doi.org/10.4236/jct.2019.102010

Received: January 6, 2019

Accepted: February 12, 2019

Published: February 15, 2019

Copyright (c) 2019 by author(s) and Scientific Research Publishing Inc. This work is licensed under the Creative Commons Attribution International License (CC BY 4.0).

http://creativecommons.org/licenses/by/4.0/

\begin{abstract}
Aim: To investigative the efficacy of carbon nanoparticles (CNs) to identify the lymph nodes during radical surgery in colorectal cancer. Method: The MEDLINE, EMBASE and Cochrane Library databases were searched electronically to identify the studies that compared the use of $\mathrm{CNs}$ (CN group) with control group in patients undergoing colorectal cancer radical surgery (from January 2009 to November 2018). The primary outcome was the number of retrieved central lymph nodes. Results: This meta-analysis identified 2 randomized controlled trials and 5 non-randomized controlled trials. Compared with the control group, the $\mathrm{CN}$ group resulted in an average of 7.16 more lymph nodes removed per patient $(\mathrm{WMD}=7.16,95 \% \mathrm{CI}=3.76$ to $10.57, p<0.01$ ), 7.26 minutes less required for retrieving lymph nodes (WMD $=-7.26,95 \% \mathrm{CI}=-13.43$ to $-1.09, p=0.02)$, and $15.1 \mathrm{ml}$ less blood loss during operation (WMD $=-15.11,95 \% \mathrm{CI}=-23.15$ to $-7.06, p<0.01$ ). Although there was no significant difference in the metastatic lymph nodes between the two groups $(\mathrm{OR}=1.02,95 \% \mathrm{CI}=0.79$ to $1.31, p=0.87$ ), there was 1.45 times more metastatic lymph of the stained nodes in $\mathrm{CN}$ group than in the control group $(\mathrm{OR}=1.45,95 \% \mathrm{CI}=1.13$ to $1.85, p<0.01)$. In addition, lymph nodes less than $5 \mathrm{~mm}$ were detected significantly more in the $\mathrm{CN}$ group than in the control group $(\mathrm{OR}=2.15,95 \% \mathrm{CI}=1.77$ to $2.63, p<0.01)$. Conclusions: The technique of $\mathrm{CNs}$ labeled lymph node staining in curative colorectal carcinoma is easy and effective, which can improve the retrieved number of lymph nodes, especially for nodes $<5 \mathrm{~mm}$. The black stained lymph node indicates higher risk of metastasis. Further high quality RCT is needed to verify these conclusions.
\end{abstract}




\section{Keywords}

Carbon Nanoparticles, Lymph Node, Colorectal Cancer

\section{Introduction}

Radical colorectal surgery is the main treatment for colorectal cancer [1]. The lymph node is the main way of colorectal cancer metastasis, so, it has a prognosis and therapeutic importance to stage lymph node metastasis accurately in patients with colorectal cancer [2]. In order to improve the accuracy of tumor staging, lymph node detection should be included as much as possible for pathological examination [3]. However, the traditional finger-pressure palpation method is time-consuming and easy to miss lymph nodes [4], especially the small lymph nodes and these lymph nodes also have the possibility of metastasis; small metastatic lymph node remnants are important causes of postoperative recurrence and death [5]. There are lots of studies reported; with the application of tracer, the retrieved rate of lymph nodes can be improved, especially the small ones [6] [7].

The carbon nanoparticles (CNs) can be injected as a suspension that can enter the lymphatic capillaries rather than the capillary vessels [8] [9]. After macrophage phagocytosis, CNs quickly gathers in the lymph nodes and dyes them black [10]. Because CNs are with high lymphatic system trends and specificity, their guidance value in the detection of the lymph node in a variety of solid tumor radical surgery has been confirmed [11]. However, no systematic review about the CNs value in radical colorectal surgery was reported.

Therefore, this meta-analysis was designed to evaluate the efficacy of CNs during radical colorectal surgery. This study included all comparative researches using $\mathrm{CNs}$ as a tracer for lymph node dissection or not during radical surgery for colorectal cancer. By summarizing initial recommendations on the injection site and total dose, and waiting time for the use of $\mathrm{CNs}$ in these studies, we can investigate the relationship between the number of nodes retrieved and the rate of node positivity, and evaluate the effect of submucosal $\mathrm{CNs}$ staining on improvements in lymph node detection and staging accuracy.

\subsection{Identification of Trials}

MEDLINE, EMBASE, PubMed, the Web of Science, and the Cochrane Library databases were systematically searched for all comparative studies from January 2009 to November 2018, using the keywords carbon nanoparticles, lymph node, colorectal cancer. The reference lists of relevant articles were manually searched to identify other relevant trials. Only trials published in English or Chinese were included. Studies in animals and review articles were excluded. Studies identified through the search were independently screened by two authors (Miao Liu and Ai Shen) for inclusion. Any disagreements were arbitrated by a third author 
(Hao Sun).

Inclusion Criteria

Studies met the following criteria characteristics can included in this study. Included articles must compare the use of $\mathrm{CNs}$ with at least 1 control group which did not use a tracer during colorectal cancer under radical surgery. Only randomized controlled study (RCT) and non-randomized comparative study (NRCT) were included.

Subjects

Patients underwent a radical surgery for colorectal cancer with a diagnosis confirmed by pathology results.

Interventions

Patients in the experimental group were injected with CNs before surgery, and patients in the control group did not receive an injection of tracer.

Observation Indexes

The primary outcome was the number of retrieved central lymph nodes per patient. Other outcomes included the staining rates of lymph nodes, the rates of metastatic nodes in all retrieved central lymph nodes, operation time, time for dissection lymph nodes, blood loss, total number of lymph nodes and small ones $(<5 \mathrm{~mm})$. At least 1 index was described separately for each study group.

Exclusion Criteria

Non-independent clinical controlled trials, studies with a patient number < 15 , or studies with incomplete data were excluded.

\subsection{Quality Assessment}

The quality of RCT studies was assessed according to the Jadad scoring system. The scale consists of 3 items: randomization ( 0 - 2 points), blinding ( $0-2$ points), and descriptions of the withdrawals and dropouts ( 0 or 1 point). The total possible score was 5 points. Trials with a score of 0 to 2 were considered to be of low quality, and those with a score of 3 to 5 were considered to be of high quality (Table 2). For NRCTs, the Newcastle-Ottawa Scale was used (Table 3).

\subsection{Statistical Analysis}

All analysis was performed with Rev Man 5.2. Based on the results of heterogeneity tests and study designs, a random effects model was used for all analyses. Weighted mean differences (WMDs) were calculated for the continuous outcome variables, and odd ratios (ORs) and risk differences (RDs) were calculated for the dichotomous outcome variables. In addition, 95\% confidence intervals (CIs) were calculated for the WMDs, ORs, and RDs. Differences were considered to be statically significant at $p<0.05$. A sensitivity analysis was performed to exclusively examine the pooled results of these studies. If result of the comparison had changed, the result was presented. 


\section{Results}

\subsection{Study Selection and Description}

A total of 156 references were initially identified. After reading titles and abstracts, 35 references were eliminated for non-colorectal cancers' study. Additional 28 references were excluded for non-clinical studies, duplicate publication and non-controlled trials (Figure 1). After carefully evaluating, there were 7 studies with high quality met the inclusion criteria [12]-[18]. Thus, 7 studies, including 921 patients, were included in this study (Table 1). Of the 921 patients, 531 (57.7\%) patients in CN group, 390 (42.3\%) patients in control group.

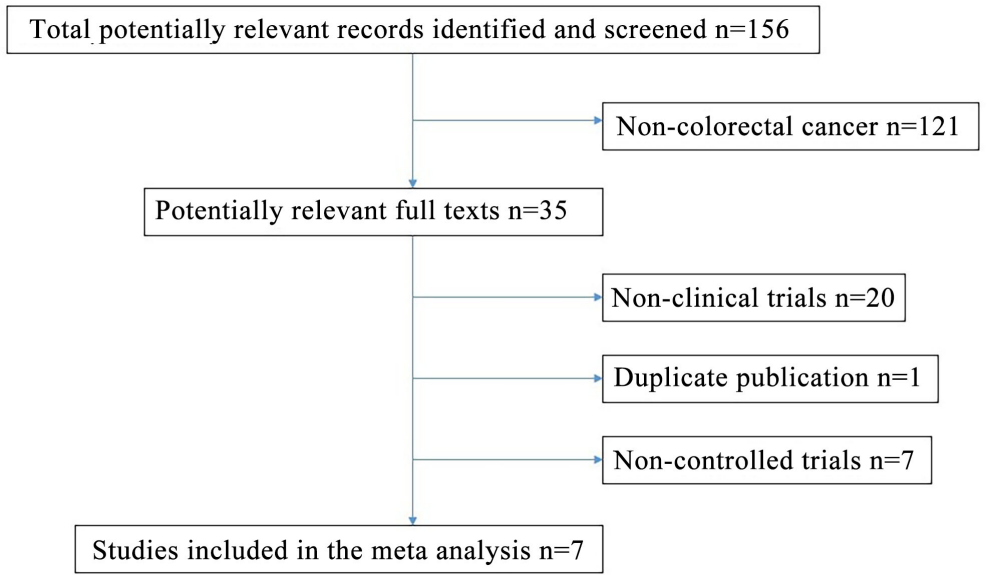

Figure 1. Flowchart showing the screening procedure used in the study.

Table 1. Characteristics of the 7 articles included in the meta-analysis.

\begin{tabular}{|c|c|c|c|c|c|c|c|c|}
\hline Study & $\begin{array}{l}\text { Tumor } \\
\text { Type }\end{array}$ & Number & $\begin{array}{l}\text { Study } \\
\text { Design }\end{array}$ & $\begin{array}{l}\text { Injection } \\
\text { Site }\end{array}$ & $\begin{array}{c}\text { Dose } \\
\mathrm{ml}\end{array}$ & $\begin{array}{l}\text { Waiting } \\
\text { Time }\end{array}$ & Laparoscopic & Indices \\
\hline Cai et al. [13] & Colorectal & 60 & RCT & $\begin{array}{l}\text { 4-quadrant region } \\
\text { around the mass }\end{array}$ & 1 & $10 \mathrm{~min}$ & No & (1)(4)(9) \\
\hline Zhang et al. [17] & Rectal & 87 & NRCT & $\begin{array}{c}\text { Around the submucosa } \\
\text { of the rectum }\end{array}$ & 5 & $30 \mathrm{~min}$ & In $96 \%$ cases & (1)(4) \\
\hline Wang et al. $[18]$ & Rectal & 152 & NRCT & $\begin{array}{l}3 \text { points around the } \\
\text { submucosal layer of mass }\end{array}$ & 0.5 & 1 day & in $97 \%$ cases & (1)(2) 8 \\
\hline Yang et al. [12] & Colorectal & 65 & RCT & $\begin{array}{l}4 \text { - } 6 \text { points } \\
\text { around the mass }\end{array}$ & $0.15-0.25$ & $10 \mathrm{~min}$ & Yes & (1)(2)(3)(4) \\
\hline Zhang et al. [16] & Colorectal & 53 & NRCT & $\begin{array}{l}4 \text { points around the } \\
\text { submucosal layer of mass }\end{array}$ & $0.15-0.25$ & 1 - 3 day & Yes & (1)(2)(3)(4)(8) \\
\hline Wang et al. $[15]$ & Colorectal & 54 & NRCT & $\begin{array}{l}4 \text { points around the } \\
\text { submucosal layer of mass }\end{array}$ & 1 & $10 \mathrm{~min}$ & Yes & (1)(5)(7) 8 \\
\hline Wang et al. & Colorectal & 470 & NRCT & $\begin{array}{l}4-6 \text { points } \\
\text { around the mass }\end{array}$ & 1 & $30 \mathrm{~min}$ & No & (1)(2)(5)(7) \\
\hline
\end{tabular}

Observation indices: (1) the number of retrieved lymph nodes in the $\mathrm{CN}$ and control groups, (2) the total metastatic rate of the retrieved lymph nodes in the $\mathrm{CN}$ and control groups, (3) the metastatic rate of stained/non-stained lymph nodes in the $\mathrm{CN}$ and control groups, (4) the number of tiny lymph nodes ( $<5$ $\mathrm{mm}$ ) in the $\mathrm{CN}$ and control groups, (5) the surgical time in the $\mathrm{CN}$ and control groups, (6) the lymph node dissection time between the $\mathrm{CN}$ and control groups, (7) the surgical blood loss in the $\mathrm{CN}$ and control groups, (8) the number of patients who had dissected lymph nodes $>12$ in the $\mathrm{CN}$ and control groups, and (9) the number of lymph nodes in the $\mathrm{CN}$ and $\mathrm{MB}$ groups. $\mathrm{CN}$ : carbon nanoparticles; MB: methylene blue. 
Table 2. Details of quality assessment of RCTs.

\begin{tabular}{cccccc}
\hline Study & Randomization & $\begin{array}{c}\text { Concealment of } \\
\text { Allocation }\end{array}$ & Blinding & $\begin{array}{c}\text { Loss to } \\
\text { Follow-Up, \% }\end{array}$ & $\begin{array}{c}\text { Quality } \\
\text { Assessment }\end{array}$ \\
\hline Cai et al. $[13]$ & $\begin{array}{c}\text { No detailed } \\
\text { description }\end{array}$ & $\begin{array}{c}\text { Only mentioned } \\
\text { randomized }\end{array}$ & Unclear & 0 & 2 \\
$\begin{array}{c}\text { Yang } \text { et al. } \\
{[12]}\end{array}$ & $\begin{array}{c}\text { Divided randomly } \\
\text { into label group }\end{array}$ & $\begin{array}{c}\text { Sealed } \\
\text { envelopes }\end{array}$ & No blinding & 0 & 3 \\
\hline
\end{tabular}

Table 3. Details of the quality assessment of nonrandomized controlled trial.

\begin{tabular}{cccccc}
\hline \multicolumn{1}{c}{ Study } & Study Design & Selection & Comparability & Exposure & $\begin{array}{c}\text { Quality } \\
\text { Assessment }\end{array}$ \\
\hline Zhang et al. [17] & $\begin{array}{c}\text { Prospective } \\
\text { controlled study }\end{array}$ & 4 & 2 & 2 & 8 \\
Wang et al. [18] & $\begin{array}{c}\text { Prospective } \\
\text { controlled study }\end{array}$ & 4 & 2 & 2 & 8 \\
Zhang et al. [16] & $\begin{array}{c}\text { Prospective } \\
\text { controlled study }\end{array}$ & 3 & 2 & 2 & 7 \\
Wang et al. [15] & $\begin{array}{c}\text { Retrospective } \\
\text { study }\end{array}$ & 3 & 2 & 2 & 6 \\
Wang et al. [14] & $\begin{array}{c}\text { Prospective } \\
\text { controlled study }\end{array}$ & 4 & 2 & 2 & 8 \\
\hline
\end{tabular}

Study characteristics and quality assessment. Two of the 5 studies were RCTs, involving 125 patients [12] [13]. Three of the 5 studies were NRCTs, involving 796 patients. All patients had confirmed colorectal cancer, based on postoperative pathologic examinations. The characteristics of the 5 included studies are presented in Table 1. Most investigators preferred multipoint injections ( 3 to 6 points) around the tumor, with a total CNs dose of 0.15 to $5 \mathrm{ml}$ and a 10 minutes to 3 days wait before surgery.

\section{Intervention Effects}

Number and metastatic rate of retrieved lymph nodes in the $\mathrm{CN}$ group and control group:

Compared with the control group, the use of CNs resulted in an average of 7.16 more lymph nodes removed per patient ( $\mathrm{WMD}=7.16,95 \% \mathrm{CI}=3.76$ to $10.57, p<0.01$, Figure 2$)$, with high heterogeneity $\left(I^{2}=95 \%, p<0.01\right)$. Meta-analysis demonstrated that the total metastatic rate of the retrieved lymph node was not significantly different between the $\mathrm{CN}$ and control group $(\mathrm{OR}=$ $1.09,95 \% \mathrm{CI}=0.84$ to $1.41, p=0.53$, Figure 3 ). But of the metastatic rate, the stained lymph nodes of $\mathrm{CN}$ group was 1.45 times more than the control group which didn't use the tracer technique ( $\mathrm{OR}=1.45,95 \% \mathrm{CI}=1.13$ to $1.85, p<$ 0.01 , Figure 4). Two studies have reported these data. Similarly, according to these two studies above, there was no significant differences between the 
non-stained lymph nodes in the $\mathrm{CN}$ group and the found lymph nodes in the control group ( $\mathrm{OR}=1.31,95 \% \mathrm{CI}=0.64$ to $2.65, p=0.46$, Figure 5 ). Only two researches have statistically reported detection rates for the tiny lymph nodes which diameter $<5 \mathrm{~mm}$ in both groups and found that the number rate of the tiny lymph node was significant higher in the $\mathrm{CN}$ group than the control group $(\mathrm{OR}=2.32,95 \% \mathrm{CI}=1.69$ to $3.18, p<0.01$, Figure 6$)$. The comparison of patients with detected LNs numbers excess than 12 was reported in 3 studies, and the pooled results showed that the $\mathrm{CN}$ group was significantly superior to the control group $(\mathrm{OR}=13.03,95 \% \mathrm{CI}=2.79$ to $60.96, p<0.01$, Figure 7$)$.

\subsection{Operation Situation}

There's a small amount of studies reported the time of surgery, with respect to the general surgical time, the $\mathrm{CN}$ group is slightly less than the control group ( $\mathrm{WMD}=-7.54,95 \% \mathrm{CI}=-13.81$ to $-1.28, p=0.02$, Figure 8). Meanwhile, the $\mathrm{CN}$ group has shorter lymph node dissection times $(\mathrm{WMD}=-7.30,95 \% \mathrm{CI}=$ -8.51 to $-6.09, p<0.01$, Figure 9) and less surgical blood loss (WMD $=-15.11$, $95 \% \mathrm{CI}=-23.15$ to $-7.06, p<0.01$, Figure 10 ).

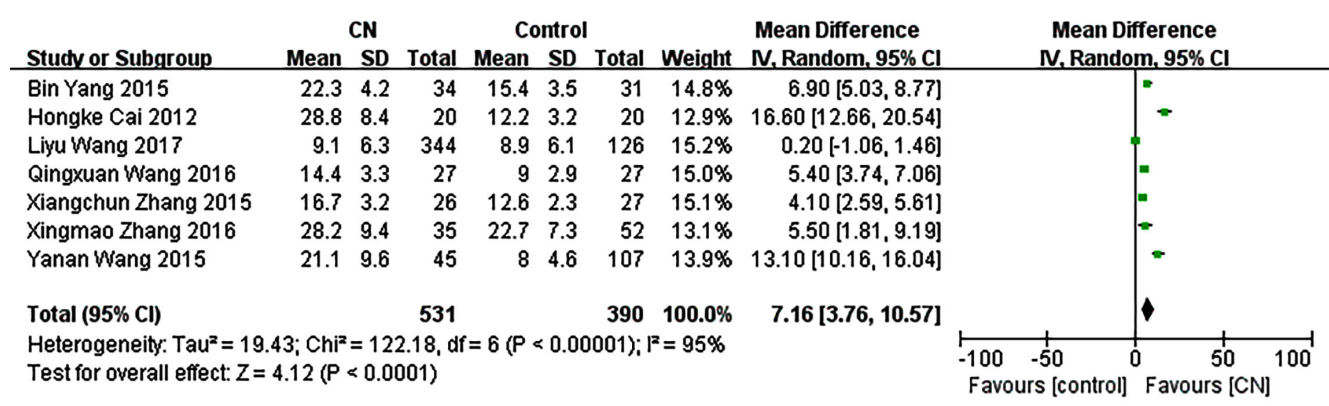

Figure 2. Total lymph nodes in the $\mathrm{CN}$ and control groups.

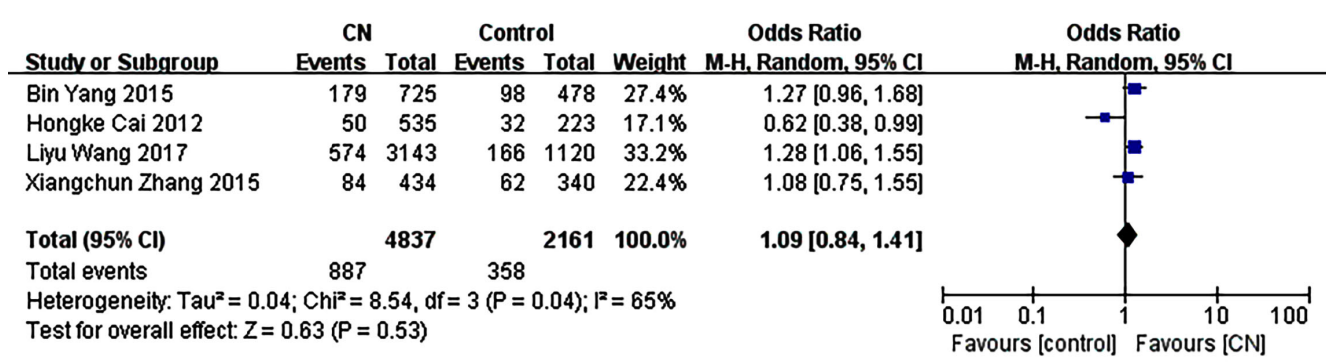

Figure 3. Total metastatic lymph nodes in the $\mathrm{CN}$ and control groups.

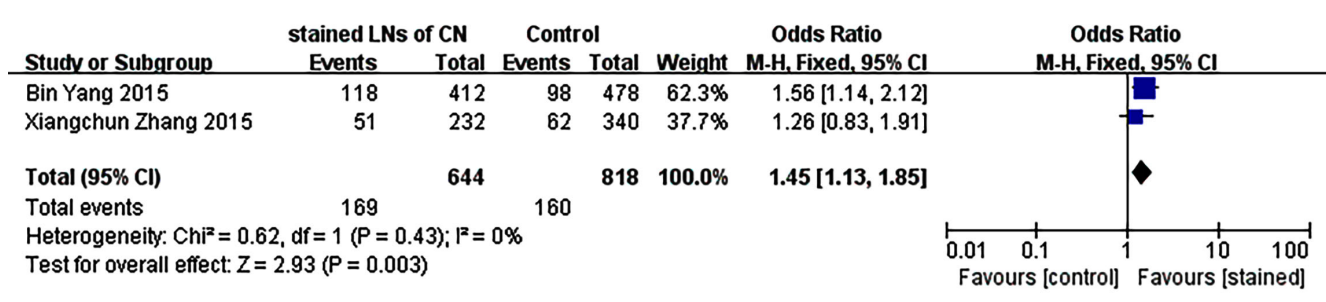

Figure 4. Metastatic lymph nodes in stained lymph nodes of $\mathrm{CN}$ and control group. 


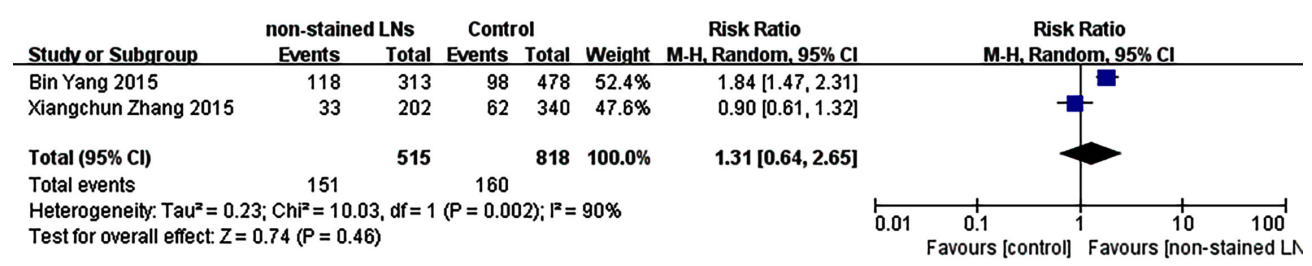

Figure 5. Metastatic lymph nodes in non-stained lymph nodes of $\mathrm{CN}$ and control group.

\begin{tabular}{|c|c|c|c|c|c|c|c|c|}
\hline Studv or Subgroup & $\begin{array}{r}\text { CN } \\
\text { Events }\end{array}$ & Total & $\begin{array}{c}\text { Contrc } \\
\text { Events }\end{array}$ & $\begin{array}{l}\text { ol } \\
\text { Total }\end{array}$ & Weight & $\begin{array}{c}\text { Odds Ratio } \\
\text { M-H. Fixed, } 95 \% \mathrm{Cl}\end{array}$ & $\begin{array}{r}\text { Odds } \\
\text { M-H. Fixe }\end{array}$ & $\begin{array}{l}\text { s Ratio } \\
\text { ed. } 95 \% \mathrm{Cl}\end{array}$ \\
\hline Bin Yang 2015 & 33 & 725 & 10 & 478 & $21.1 \%$ & $2.23[1.09,4.57]$ & & \\
\hline Xiangchun Zhang 2015 & 137 & 434 & 56 & 340 & $78.9 \%$ & $2.34[1.65,3.32]$ & & \\
\hline Total $(95 \% \mathrm{Cl})$ & & 1159 & & 818 & $100.0 \%$ & $2.32[1.69,3.18]$ & & \\
\hline Total events & 170 & & 66 & & & & & \\
\hline \multicolumn{7}{|c|}{$\begin{array}{l}\text { Heterogeneity: } \mathrm{Chi}^{2}=0.01, \mathrm{df}=1(P=0.91) ; \mathrm{I}^{2}=0 \% \\
\text { Test for overall effect: } Z=5.22(P<0.00001)\end{array}$} & \begin{tabular}{cc|}
0.01 & 0.1 \\
Favours [control]
\end{tabular} & ]$_{\text {Favours }[\mathrm{CN}]}^{10} 100$ \\
\hline
\end{tabular}

Figure 6. Tiny lymph node in $\mathrm{CN}$ and control group.

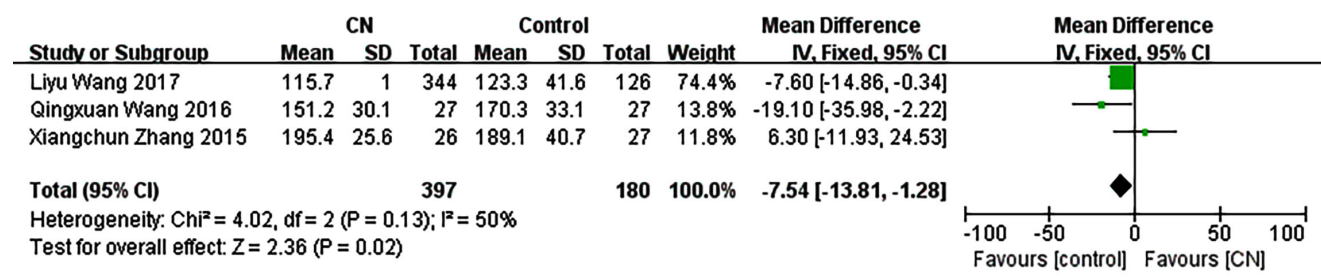

Figure 7. The number of patients of detected LNs $>12$ in $\mathrm{CN}$ and control group.

\begin{tabular}{|c|c|c|c|c|c|c|c|c|}
\hline Study or Subgroup & $\begin{array}{r}\text { CN } \\
\text { Events }\end{array}$ & Total & $\begin{array}{l}\text { Contr } \\
\text { Events }\end{array}$ & Total & Weight & $\begin{array}{c}\text { Odds Ratio } \\
\text { M-H, Random, } 95 \% \mathrm{Cl}\end{array}$ & $\begin{array}{r}\text { Odds } \\
\text { M.H, Rand }\end{array}$ & $\begin{array}{l}\text { Ratio } \\
\text { lom, } 95 \% \mathrm{Cl}\end{array}$ \\
\hline Qingxuan Wang 2016 & 19 & 27 & 10 & 27 & $40.1 \%$ & $4.04[1.30,12.58]$ & & $\longrightarrow$ \\
\hline Xiangchun Zhang 2015 & 26 & 26 & 18 & 27 & $18.2 \%$ & $27.22[1.49,497.18]$ & & \\
\hline Yanan Wang 2015 & 40 & 45 & 23 & 107 & $41.7 \%$ & $29.22[10.35,82.48]$ & & \\
\hline Total $(95 \% \mathrm{Cl})$ & & 98 & & 161 & $100.0 \%$ & $13.03[2.79,60.96]$ & & \\
\hline Total events & 85 & & 51 & & & & & \\
\hline \multicolumn{6}{|c|}{$\begin{array}{l}\text { Heterogeneity: } \mathrm{Tau}^{2}=1.21 ; \mathrm{Chi}^{2}=6.69, \mathrm{df}=2(P=0.04) ; I^{2}=70 \% \\
\text { Test for overall effect: } Z=3.26(P=0.001)\end{array}$} & & $\begin{array}{cc}0.01 & 0.1 \\
\text { Favours [control] }\end{array}$ & ${ }_{\text {Favours [CN] }}^{1} 100$ \\
\hline
\end{tabular}

Figure 8. The time of surgery in $\mathrm{CN}$ and control group.

\begin{tabular}{|c|c|c|c|c|c|c|c|c|c|c|}
\hline \multirow[b]{2}{*}{ Study or Subgroup } & \multicolumn{2}{|r|}{$\mathrm{CN}$} & \multicolumn{3}{|c|}{ Control } & \multirow[b]{2}{*}{ Total } & \multirow[b]{2}{*}{ Weight } & \multirow{2}{*}{$\begin{array}{l}\text { Mean Difference } \\
\text { IV. Fixed, } 95 \% \mathrm{Cl}\end{array}$} & \multirow{2}{*}{\multicolumn{2}{|c|}{$\begin{array}{l}\text { Mean Difference } \\
\text { N. Fixed, } 95 \% \mathrm{Cl}\end{array}$}} \\
\hline & Mean & SD & Total & Mean & SD & & & & & \\
\hline Liyu Wang 2017 & 50.7 & 28.1 & 344 & 63.7 & 49.4 & 126 & $77.8 \%$ & $-13.00[-22.12,-3.88]$ & & \\
\hline Qingxuan Wang 2016 & 125 & 29.5 & 27 & 147.5 & 34.4 & 27 & $22.2 \%$ & $-22.50[-39.59,-5.41]$ & & \\
\hline Total $(95 \% \mathrm{Cl})$ & & & 371 & & & 153 & $100.0 \%$ & $-15.11[-23.15,-7.06]$ & & \\
\hline $\begin{array}{l}\text { Heterogeneity: } \mathrm{Chi}^{2}=0 \\
\text { Test for overall effect: } Z\end{array}$ & $\begin{array}{l}2, \mathrm{df}= \\
=3.68(F\end{array}$ & $\begin{array}{l}1(P=0 \\
=0.00\end{array}$ & $\begin{array}{l}0.34) ; I^{-1} \\
002)\end{array}$ & $=0 \%$ & & & & & $\begin{array}{l}-100-50 \\
\text { Favours [control] }\end{array}$ & ${ }_{\text {Favours }[\mathrm{CN}]}^{50} 100$ \\
\hline
\end{tabular}

Figure 9. The time of lymph node dissection times in $\mathrm{CN}$ and control group.

\begin{tabular}{|c|c|c|c|c|c|c|c|c|c|c|}
\hline Stucty or Subgroup & \multicolumn{3}{|c|}{ CN } & $\begin{array}{l}\text { Co } \\
\text { Mean }\end{array}$ & \multicolumn{2}{|c|}{ Control } & \multicolumn{2}{|r|}{ Mean Difference } & \multicolumn{2}{|c|}{$\begin{array}{l}\text { Mean Difference } \\
\text { N. Fixed, } 95 \% \mathrm{Cl}\end{array}$} \\
\hline $\begin{array}{l}\text { Hongyuan Chen } 2014 \\
\text { Yanan Wang } 2015\end{array}$ & $\begin{array}{l}23.5 \\
27.6\end{array}$ & $\begin{array}{l}4.8 \\
3.5\end{array}$ & $\begin{array}{l}20 \\
45\end{array}$ & $\begin{array}{l}32.6 \\
34.6\end{array}$ & $\begin{array}{l}5.5 \\
4.3\end{array}$ & $\begin{array}{r}20 \\
10 ?\end{array}$ & $\begin{array}{l}14.3 \% \\
85.7 \%\end{array}$ & $\begin{array}{r}-9.10[-12.30,-5.90] \\
-7.00[-8.31,-5.69]\end{array}$ & $=$ & \\
\hline Total (95\% Cl) & & & 65 & & & 127 & $100.0 \%$ & $-7.30[-8.51,-6.09]$ & 1 & \\
\hline $\begin{array}{l}\text { Heterogeneity: } \mathrm{Chi}^{2}=1 \\
\text { Test for overall effect: } Z\end{array}$ & $\begin{array}{l}2, \mathrm{df}=1 \\
11.82\end{array}$ & $\begin{array}{l}(P= \\
P<0\end{array}$ & $\begin{array}{l}0.23) ; \\
.00001\end{array}$ & $\begin{array}{l}p^{2}=299 \\
\text { 1) }\end{array}$ & & & & & $\begin{array}{ll}-100 & -50 \\
\text { Favours [control] }\end{array}$ & \begin{tabular}{|cc}
50 & 100 \\
Favours [CN]
\end{tabular} \\
\hline
\end{tabular}

Figure 10. The surgical blood loss in $\mathrm{CN}$ and control group. 


\section{Discussion}

Carbon nanosuspensions have highly lymphoid system tropism with an average diameter of $100 \mathrm{~nm}$ [19]. When injected into local tissue, it can be quickly consumed by macrophages. Due to the gap of capillary endothelial cells is 20 - 50 $\mathrm{nm}$, and the gap of capillary lymphatic endothelial cell is $120-150 \mathrm{~nm}$, and the basal membrane is not growth completely, so the CNs were not enter into the blood vessels but quickly enter into the lymphatic vessels, and stranded in the lymph nodes, dyed the lymph node to black, fulfilled the vital staining of tumor areas, achieved the tracer role [20].

At present, the advantages of laparoscopic radical resection for colon cancer have been widely recognized and this micro-invasive method was written into the NCCN guidelines for colon cancer treatment. This method has become the standard surgical procedure for colon cancer. In addition, laparoscopic surgery for rectal cancer has also been widely carried out [21].

Laparoscopic surgery for colorectal cancer has a magnification effect of 2 - 3 times, with clear anatomical space and structure, which is easy to identification and conducive to nerve protection and lymph node dissection, as well as complete mesenteric resection (CME) and total mesenteric resection (TME) [22]. However, the current standard of laparoscopic lymph node dissection of TME and CME in colorectal cancer surgery are difficult to achieve generally due to the level differed in different hospitals and doctors [23]. The most important metastatic route of colorectal cancer is through the lymph nodes pathway, and positive lymph node residue is an important cause of recurrence and death [24]. In particularly, about $8 \%$ - 12\% colorectal cancer may have lymph node metastasis. Therefore, how to ensure the dissection of D3 lymph node and the realization of TME and CME are important clinical challenges at present, especially in Laparoscopic colorectal cancer surgery [25]. In this study, it was found that carbon nanoparticle tracer technology can help solve these problems. It has been report that that $\mathrm{CNs}$ in the operation is helpful for detect the sentinel lymph node, because the dyeing time is short, and the lymph node staining of each station is insufficient, so, injecting CNs into tumor area 1 - 3 days before operation may help the lymph node at each stage fully stained, and these lymph nodes can be used to clean the lymph nodes at all sites and avoid missing cancerous tissue [26]. For the staining lymph nodes other than the third station, the lymph nodes need not be routinely cleaned, but can be excised and sent to rapid frozen pathological examination [27]. In colorectal surgery, lymph nodes in the corresponding area should be cleaned if there is metastasis, and nerve damage should be avoided if there is no metastasis. Therefore, for beginners of laparoscopic colorectal surgery with inadequate management, the standard D3 lymph node cleaning is hard to reach. However, using $\mathrm{CNs}$ lymph tracer technology can guide intraoperative lymph node cleaning, ensure the D3 radical surgery done, and help handle with the black dye lymph nodes beyond D3 stage if needed [28]. Therefore, the use of carbon nanoparticles can reduce surgery time and reduce 
bleeding.

CNs can improve the detection rate of lymph nodes, guide pathological staging and postoperative adjuvant therapy. From the 2010 Edition of NCCN guidelines for the diagnosis and treatment of colorectal cancer, sufficient number of lymph nodes no less than 12 should be included in the postoperative pathological examination to ensure the accuracy and reliability of the pathological result evaluation and guide the postoperative adjuvant treatment [3]. However, most of the lymph nodes detected by pathologists are retrieved by hand without a tracer, and their sensitivity is very low. Many of the smaller lymph nodes are hidden in the mesenterium and fat, these lymph nodes cannot be easily touched, so it is difficult to guarantee the number of detected lymph nodes. Some studies have found that $45.4 \%$ metastatic lymph nodes are small lymph nodes with a diameter less than $5 \mathrm{~mm}$, which is easy to be omitted, leading to low pathological staging and ultimately affecting the assessment of treatment and prognosis [29]. Lymph nodes stained black with $\mathrm{CNs}$ are easy to identify and can help pathologists find these tiny metastatic nodes more quickly and more often. This systematic analysis shows that the $\mathrm{CN}$ stained can effectively improve the detected number of lymph nodes, especially the small lymph nodes, and improve the accuracy of pathological staging.

This study has some limitations. First, the available articles were limited to English or Chinese publications. No publications written in other languages were included. The quality assessment scores of the 2 included randomized controlled trials were relatively low with the lack of blinding; the other 5 studies were nonrandomized controlled trial. Thus, further research is needed to verify the conclusions in the present study.

\section{Conclusion}

Carbon nanoparticles are helpful in curative colorectal surgery. CNs can improve the retrieved number of lymph nodes, especially for nodes $<5 \mathrm{~mm}$. The black stained lymph node indicates higher risk of metastasis. A large scale high quality randomized controlled study is needed to verify these conclusions.

\section{Funding Information}

This study was supported by the project from Chongqing Science and Technology Bureau (cstc2018jscx-msybX0156).

\section{Conflicts of Interest}

The authors declare no conflicts of interest regarding the publication of this paper.

\section{References}

[1] Zippi, M., De Toma, G., Minervini, G., et al. (2017) Desmoplasia Influenced Recurrence of Disease and Mortality in Stage III Colorectal Cancer within Five Years after 
Surgery and Adjuvant Therapy. Saudi Journal of Gastroenterology, 23, 39-44. https://doi.org/10.4103/1319-3767.199114

[2] Sprenger, T., Rothe, H., Conradi, L.C., et al. (2016) Stage-Dependent Frequency of Lymph Node Metastases in Patients with Rectal Carcinoma after Preoperative Chemoradiation: Results from the CAO/ARO/AIO-94 Trial and from a Comparative Prospective Evaluation with Extensive Pathological Workup. Diseases of the Colon \& Rectum, 59, 377-385. https://doi.org/10.1097/DCR.0000000000000570

[3] Edge, S.B. and Compton, C.C. (2010) The American Joint Committee on Cancer: The 7th Edition of the AJCC Cancer Staging Manual and the Future of TNM. Annals of Surgical Oncology, 17, 1471-1474.

https://doi.org/10.1245/s10434-010-0985-4

[4] Kotake, K., Honjo, S., Sugihara, K., et al. (2012) Number of Lymph Nodes Retrieved Is an Important Determinant of Survival of Patients with Stage II and Stage III Colorectal Cancer. Japanese Journal of Clinical Oncology, 42, 29-35. https://doi.org/10.1093/jjco/hyr164

[5] Nelson, H., Petrelli, N., Carlin, A., et al. (2001) Guidelines 2000 for Colon and Rectal Cancer Surgery. Journal of the National Cancer Institute, 93, 583-596. https://doi.org/10.1093/jnci/93.8.583

[6] Yoshimatsu, K., Ishibashi, K., Umehara, A., et al. (2005) How Many Lymph Nodes Should Be Examined in Dukes' B Colorectal Cancer? Determination on the Basis of Cumulative Survival Rate. Journal of Hepato-Gastroenterology, 52, 1703-1706.

[7] Washington, M.K., Berlin, J., Branton, P.A., et al. (2008) Protocol for the Examination of Specimens from Patients with Primary Carcinomas of the Colon and Rectum. Archives of Pathology \& Laboratory Medicine, 132, 1182-1193.

[8] Dai, L.C., Yao, X., Wang, X., et al. (2009) In Vitro and in Vivo Suppression of Hepatocellular Carcinoma Growth by Midkine-Antisense Oligonucleotide-Loaded Nanoparticles. World Journal of Gastroenterology, 15, 1966-1972. https://doi.org/10.3748/wjg.15.1966

[9] Wu, T., Zheng, W.L., Zhang, S.Z., et al. (2011) Bimodal Visualization of Colorectal Uptake of Nanoparticles in Dimethylhydrazine-Treated Mice. World Journal of Gastroenterology, 17, 3614-3622. https://doi.org/10.3748/wjg.v17.i31.3614

[10] Madru, R., Kjellman, P., Olsson, F., et al. (2012) 99mTc-Labeled Superparamagnetic Iron Oxide Nanoparticles for Multimodality SPECT/MRI of Sentinel Lymph Nodes. Journal of Nuclear Medicine, 53, 459-463. https://doi.org/10.2967/jnumed.111.092437

[11] Lian, H.Y., Hu, M., Liu, C.H., et al. (2012) Highly Biocompatible, Hollow Coordination Polymer Nanoparticles as Cisplatin Carriers for Efficient Intracellular Drug Delivery. Chemical Communications, 48, 5151-5153.

https://doi.org/10.1039/c2cc31708g

[12] Yang, B., Li, Y., Wen, R., et al. (2015) Application of Carbon Nanoparticles Labeled Lymph Node Staining in Curative Laparoscopic Resection for Colorectal Carcinoma. Zhonghua Wei Chang Wai Ke Za Zhi, 18, 549-552.

[13] Cai, H.K., He, H.F., Tian, W., et al. (2012) Colorectal Cancer Lymph Node Staining by Activated Carbon Nanoparticles Suspension in Vivo or Methylene Blue in Vitro. World Journal of Gastroenterology, 18, 6148-6154. https://doi.org/10.3748/wjg.v18.i42.6148

[14] Wang, L.Y., Li, J.H., Zhou, X., et al. (2017) Clinical Application of Carbon Nanoparticles in Curative Resection for Colorectal Carcinoma. OncoTargets and Therapy, 10, 5585-5589. https://doi.org/10.2147/OTT.S146627 
[15] Wang, Q., Chen, E., Cai, Y., et al. (2016) Preoperative Endoscopic Localization of Colorectal Cancer and Tracing Lymph Nodes by Using Carbon Nanoparticles in Laparoscopy. World Journal of Surgical Oncology, 14, 231. https://doi.org/10.1186/s12957-016-0987-1

[16] Zhang, X., Wang, Y., Yan, W., et al. (2015) Application of Lymph Node Labeling with Carbon Nanoparticles in Laparoscopic Colorectal Cancer Surgery. Chinese Medical Journal, 95, 2612-2615.

[17] Zhang, X.M., Liang, J.W., Wang, Z., et al. (2016) Effect of Preoperative Injection of Carbon Nanoparticle Suspension on the Outcomes of Selected Patients with Mid-Low Rectal Cancer. Chinese Journal of Cancer, 35, 33. https://doi.org/10.1186/s40880-016-0097-z

[18] Wang, Y., Deng, H., Chen, H., et al. (2015) Preoperative Submucosal Injection of Carbon Nanoparticles Improves Lymph Node Staging Accuracy in Rectal Cancer after Neoadjuvant Chemoradiotherapy. Journal of the American College of Surgeons, 221, 923-930. https://doi.org/10.1016/j.jamcollsurg.2015.07.455

[19] van Tongeren, M.J., Kromhout, H. and Gardiner, K. (2000) Trends in Levels of Inhalable Dust Exposure, Exceedance and Overexposure in the European Carbon Black Manufacturing Industry. Annals of Occupational Hygiene, 44, 271-280. https://doi.org/10.1016/S0003-4878(99)00109-X

[20] Magrez, A., Kasas, S., Salicio, V., et al. (2006) Cellular Toxicity of Carbon-Based Nanomaterials. Nano Letters, 6, 1121-1125. https://doi.org/10.1021/nl060162e

[21] Clinical Outcomes of Surgical Therapy Study Group, Nelson, H., Sargent, D.J., et al. (2004) A Comparison of Laparoscopically Assisted and Open Colectomy for Colon Cancer. The New England Journal of Medicine, 350, 2050-2059.

[22] Bartels, S.A., Vlug, M.S., Hollmann, M.W., et al. (2014) Small Bowel Obstruction, Incisional Hernia and Survival after Laparoscopic and Open Colonic Resection (LAFA Study). British Journal of Surgery, 101, 1153-1159. https://doi.org/10.1002/bjs.9585

[23] Lujan, J., Valero, G., Hernandez, Q., et al. (2009) Randomized Clinical Trial Comparing Laparoscopic and Open Surgery in Patients with Rectal Cancer. British Journal of Surgery, 96, 982-989. https://doi.org/10.1002/bjs.6662

[24] Cho, Y.B., Lee, W.Y., Yun, H.R., et al. (2007) Tumor Localization for Laparoscopic Colorectal Surgery. World Journal of Surgery, 31, 1491-1495.

https://doi.org/10.1007/s00268-007-9082-7

[25] Benson, A.B., Venook, A.P., Bekaii-Saab, T., et al. (2014) Colon Cancer, Version 3.2014. Journal of the National Comprehensive Cancer Network, 12, 1028-1059. https://doi.org/10.6004/jnccn.2014.0099

[26] Farinella, E., Vigano, L., Fava, M.C., et al. (2013) In Vivo Lymph Node Mapping and Pattern of Metastasis Spread in Locally Advanced Mid/Low Rectal Cancer after Neoadjuvant Chemoradiotherapy. International Journal of Colorectal Disease, 28, 1523-1529. https://doi.org/10.1007/s00384-013-1727-4

[27] Shen, H., Wei, B., Feng, S., et al. (2014) Efficiency of Carbon Nanoparticles in Level VI Lymphadenectomy for Thyroid Carcinoma and Prevention of Postoperative Hypoparathyroidism. Chinese Journal of Otorhinolaryngology Head and Neck Surgery, 49, 817-820.

[28] He, H.F., Zhou, M.Q., Chen, J.Q., et al. (2012) Enhanced Lymph Node Retrieval from Colorectal Cancer Resections Using a Simple Lymphatic Staining Method. Hepatogastroenterology, 59, 375-379. https://doi.org/10.5754/hge11319 
[29] Kim, C.H., Huh, J.W., Kim, H.R., et al. (2014) Prognostic Comparison between Number and Distribution of Lymph Node Metastases in Patients with Right-Sided Colon Cancer. Annals of Surgical Oncology, 21, 1361-1368.

https://doi.org/10.1245/s10434-013-3426-3 